\title{
Valuing Changes in Frequency of Fish Stock Assessments
}

\author{
Barbara Hutniczak, Douglas Lipton, John Wiedenmann, and \\ Michael Wilberg
}

\begin{abstract}
Updating stock assessments frequently and ensuring that the most recent fishery dependent and independent data is included is a costly endeavor. We use a management strategy evaluation for the mid-Atlantic summer flounder fishery to determine the economic returns to increasing update frequencies and decreasing the data management lag. We simulate the annual acceptable biological catch for the period 2015-2040 under a range of update frequencies and data lags. We calculate present value net economic benefits for the commercial and recreational fisheries for each scenario. Discounting, the timing of harvest quotas, species specific price flexibilities and fishing cost response to biomass and quota differences suggest that the benefits gained from frequent updating and reduction in data lags will vary by fishery. For summer flounder, we find the cost of more frequent updating (1 year versus 5 years), and reducing the data management lag (1 year versus 2 years), are more than compensated for by societal benefits generated by the fishery.
\end{abstract}

Key words: data management lag, management strategy evaluation, stock assessment.

\section{Introduction}

Given the precautionary nature of the US fishery management process, where an acceptable biological catch $(\mathrm{ABC})$ is determined by a harvest control rule (HCR) designed to achieve a designated level of probability of overfishing $\left(P^{*}\right)$, actions that lead to a reduction in the uncertainty of the parameters of the underlying stock assessment model will result in a higher allowable catch (Shertzer and Prager 2007, Punt et al. 2012). Wiedenmann et al. (2017) found this to be the case using a management strategy evaluation (MSE) approach (Smith et al. 1999), where the reduction in uncertainty was due to either more frequent updating of the stock assessment with newly obtained data or decreasing the time lag from which data is collected to when it can be incorporated into the stock assessment calculations. Since more frequent updating of stock assessments and decreasing data lags are costly endeavors, we use their simulated future stream of allowable catches to compare differences in discounted net economic benefits among the scenarios.

Discounting, the timing of harvest quotas, species specific price flexibilities and fishing cost response to biomass and quota differences suggest that the benefits gained from frequent updating and reduction in data lags will vary by fishery.We use the MSE model developed by Wiedenmann et al. (2017) to characterize the population dynamics of the summer flounder (Paralichthys dentatus) stock and the

B. Hutniczak and D. Lipton. ${ }^{1}$ NOAA NMFS, Silver Spring, MD, USA

J. Wiedenmann. Rutgers University, New Brunswick, NJ, USA

M. Wilberg. Chesapeake Biological Laboratory, Solomons, MD, USA

${ }^{1}$ Corresponding author (e-mail: douglas.lipton@noaa.gov). 
resultant data generating process. The stock assessment model used is a statistical catch-at-age model and its output is used in the management model to determine the catch limit using a predefined ABC control rule.

The paper is organized as follows. First, a literature review on the value of stock assessments is presented, followed by an overview of the summer flounder fishery and its management. We then provide a description of the simulation model. Because our intent is to emphasize the added utility of evaluating returns to stock assessments in economic terms, we discuss each of the components of the economic analysis separately and demonstrate how their inclusion alters the results relative to a baseline of current frequency of updates and data lags. First, we develop a demand model from which we can calculate consumer welfare, measured as consumer surplus - the difference between maximum willingness-topay and the amount paid totaled across consumers. Next, we calculate industry net revenue, as an approximation for measuring harvester benefits. Finally, we estimate the non-market benefits to recreational fishermen using a measure similar to consumer surplus known as compensating variation, or the amount of money that would compensate fishermen so that they were at the same level of utility as without access to the fishery. The above three welfare measures are then added together to provide an overall estimate of the net benefit of the change being evaluated.

\section{Value of Stock Assessments}

The growing numbers of fisheries managed by output controls means increasing reliance on stock assessments to determine harvest levels (Walters 1996). Frequent and reliable assessments are important in order to identify early trends in biomass so that overfishing can be avoided in the future (Mace et al. 2001). A management strategy evaluation approach which simulates the stock assessment process from a true population model that is sampled with error, thus generating a stock assessment with uncertainty (Butterworth 2007, Punt et al. 2016), is well-suited to determine the economic value of assessments.

There are many sources of and classification schemes for uncertainty affecting our understanding of population dynamics and stock responses to fishing (Francis and Shotten 1997, Charles 1998, Holland and Herrera 2009). Francis and Shotten (1997) identify six categories: (1) process, (2) observation, (3) model, (4) estimation, (5) implementation and (6) institutions. Together, they play an important role in determining the $\mathrm{ABC}$ for a given stock. Including uncertainties in the stock assessment, forecast and estimation of biological reference points allows calculation of a catch that achieves a selected level of risk. Specifically, given the pre-determined level of tolerance (probability) of exceeding the reference point, the $\mathrm{ABC}$ can be determined based on the joint distribution of the overfishing limit reference point and future population size (Shertzer et al. 2008).

Clark and Kirkwood (1986) analyze the value of stock surveys yielding information on the current stock size. The authors consider a problem of optimal harvest for a fluctuating stock and calculate the maximum expected benefit from the survey. The presented example suggests that such benefits can be substantial. However, the authors consider an assessment with no observation or model uncertainty affecting the decision and therefore the results are not very helpful when considering cases where those forms of uncertainty plays a considerable role. Sethi et al. (2005) finds that measurement (i.e., observation) uncertainty has a larger impact on fishery policy than growth (i.e., model) and implementation uncertainties, and stresses the importance of stock surveys. Analysis by Moxnes (2003) further warns that management that is subject to high measurement error needs to be cautious and precautionary. Myrseth et al. (2011) suggest that consequences of biased predictions are sensitive to the employed harvest control rule and the intensity of exploitation. Shertzer and Prager (2007) find that management action delay can have significant costs when it increases the probability of stock decline, whereas prompt management results in quicker recoveries and higher cumulative yields. Prellezo (2017) applied an expected value of information approach to the Bay of Biscay anchovy fishery to show that the value 
Hutniczak et al.

of the signal from stock surveys, measured in either landings or gross revenues, were higher, the larger the stock and the greater the variability in stock size. Zimmermann and Enberg (2017) examined the impact of reduced frequency of surveys and stock assessments, and found for the specific fisheries they examined, Northeast Atlantic blue whiting and Norwegian spring-spawning herring, lower frequencies may be an option, but call for the use of management strategy evaluation and bioeconomic analysis to demonstrate whether the cost savings are justified.

Although the importance of conducting stock assessments is commonly stressed, most analyses focus on the stochasticity of stocks (Reed 1979, Lewy and Vinther 2004, Tahvonen et al. 2013) and consequently the gains from incorporating future environmental conditions to improve stock predictions. Costello et al. (1998) used a concave profit function for Pacific Northwest coho salmon, and found considerable potential welfare gains from an improved forecast of stock size. However, they also found that forecasting beyond one year brings only small gains. Costello et al. (2001) consider natural variations in the stock and analyze how optimal management changes with stock prediction. Their results are somewhat counter intuitive in that adverse environmental conditions in the future do not necessarily lead to more conservative management in the optimum. In their case, assuming profit is linear in harvest, they find that shift towards worse environmental conditions decreases optimal current escapement and thus increases current harvest. They also find no effect of information beyond a one-year time horizon in the case of a positive relationship between harvest and stock level, suggesting forecast accuracy is more important than forecast lead time. They find, however, that downward sloping demand or an increasing marginal cost of harvest causing the returns function to be concave in harvest would motivate quota smoothing and likely lead to positive long-term revenue. Rincon et al. (2016) describe the consequences of employing environmentally-based harvest control rules for species with highly dynamic recruitment. Their findings suggest that using environmental factors in harvest control rules generally increase allowable catches and year-to-year fluctuations. Relatively little work has been done on gains associated with more frequent updating of the information in order to base management decision on more up-to-date stock estimates.

\section{Summer Flounder Case Study}

Summer flounder off the east coast of the United States is managed cooperatively by the MidAtlantic Fishery Management Council and the Atlantic States Marine Fisheries Commission. The cooperative management is necessary because a significant portion of the catch is taken from both state (0-3 miles offshore) and federal exclusive economic zone waters (3-200 miles offshore). The Council and the Commission work with the National Marine Fisheries Service (NMFS), which serves as the federal implementation and enforcement entity. The fishery is managed primarily by output controls, with $60 \%$ of the annual catch limit being allocated to the commercial fishery as a commercial quota and $40 \%$ allocated to the recreational fishery. The commercial quota is distributed among states according to fixed allocation percentages based on historical landings. Additional regulations include size limits, mesh size limitations and other requirements specified by the managing agencies in order to obtain a fishing permit. The landing limits are set to take into account a projected amount of discards and discard mortality. Recommending the annual catch targets for summer flounder is a responsibility of the Summer Flounder Monitoring Committee, which is responsible for considering all relevant sources of management uncertainty. These include uncertainty in the ability of managers to control catch (late reporting, underreporting, misreporting, etc.) and uncertainty in quantifying the true catch.

The first fishery management plan for summer flounder was developed in 1988. The summer flounder stock experienced considerable overfishing in the 1980s that lead to record low stock estimates in 1989 (figure 1).

The stock rebuilding strategy that began in the 1990s lead to declaring the stock rebuilt in 2011. Throughout the rebuilding period (1988-2002), stock assessments were conducted annually with few exceptions.In the period from 1988 to 2002, stock assessments were not conducted in 1992, 1998, 
Can. J. Fish. Aquat. Sci.

Fig. 1. Summer flounder spawning stock biomass (SSB) and catch (1982-2014).

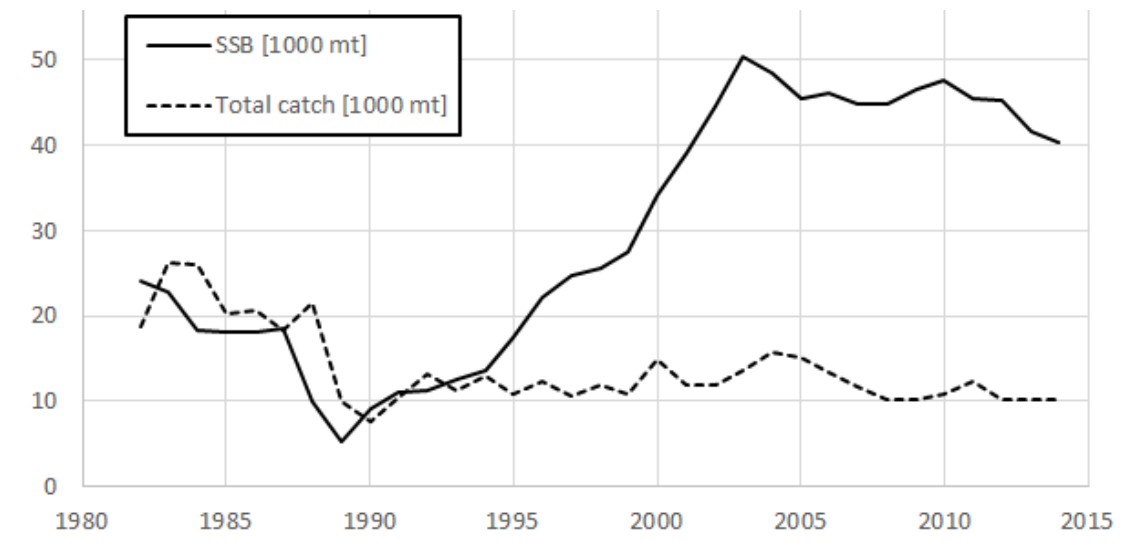

1999 and 2001. However, since the stock status has improved, stock assessments are less frequent. In the period from 2003 to 2016, there were 3 bench-mark stock assessments completed (2005, 2008 and 2013) and 7 assessment updates conducted (2006, 2009, 2010-2012, 2015-2016). All stock assessment reports can be found on NOAA NEFSC web page: http://www.nefsc.noaa.gov/saw/reviews_ report.php.

The most recent benchmark stock assessment for summer flounder was completed in 2013 and incorporated data through 2012. In 2015, NMFS updated the stock assessment with data through 2014. It indicated that the stock was not overfished, but according to the approved biological reference points, overfishing was occurring in 2014. It also provided ABC and ACL limits for 2016-2018. The update resulted in a $28 \%$ lower $\mathrm{ABC}$ in 2016 with respect to 2015 , and consequently considerably lower quotas. The 2016 assessment update with data through 2015 showed a moderate internal model retrospective pattern with continued recent underestimation of fishing mortality and overestimation of spawning stock biomass. The assessment was updated again in 2017 using data through 2016. The ABC for 2017 was re-evaluated to a value $29 \%$ lower than 2016 (11.30 mil. lb vs. $15.86 \mathrm{mil}$. lb) and resulted in an even lower commercial quota and recreational harvest limit then previously announced. The ABC for 2018 was re-estimated at a value $16 \%$ lower. The summary of previous commercial and recreational landings as well as landing limits through 2018 following the latest stock assessment update from 2017 is provided in table 1 .

Our baseline scenario considers that in the year the stock assessment is run, it uses data only through the preceding year, and the ABC and ACL specification is set for the following year, thus resulting in a two-year data management lag (DML) with a one year stock assessment update. In subsequent scenarios, the stock assessment is updated only every two, three or five years, and the ABC/ACL is held constant until the next update. In practice, the later years of the ABC/ACL specification can be revisited by the Council, if new data warrants a change. The model follows the current allocation scheme assigning $60 \%$ of the total allowable catch (TAC) to the commercial sector and $40 \%$ to the recreational fishery. Thus, we do not consider possible gains due to a more efficient allocation of quota between sectors. We also examine the potential benefits of having only a one year data management lag so that data from the year the stock assessment is being conducted is incorporated into the analysis. This may be difficult and costly to implement in practice but might be feasible for stocks where the survey data is available and processed early in the year, and harvest data is projected for the entire year from early returns. 
Hutniczak et al.

Table 1. Summary of catch limits, landings limits, and landings for commercial and recreational summer flounder fisheries from 2007 through 2018.

\begin{tabular}{|c|c|c|c|c|c|c|c|c|c|c|c|c|}
\hline Measures & 2007 & 2008 & 2009 & 2010 & 2011 & 2012 & 2013 & 2014 & 2015 & 2016 & 2017 & $2018^{c}$ \\
\hline $\mathrm{ABC}(\mathrm{mil} . \mathrm{lbs})^{a}$ & - & - & 21.50 & 25.5 & 33.95 & 25.58 & 22.34 & 21.94 & 22.57 & 16.26 & 11.30 & 13.23 \\
\hline Commercial ACL (mil. lbs) ${ }^{a}$ & - & - & - & - & - & 14.00 & 12.11 & 12.87 & 13.34 & 9.43 & 6.57 & 7.70 \\
\hline Commercial quota (mil. lbs) ${ }^{b}$ & 9.79 & 9.32 & 10.74 & 12.79 & 17.38 & 12.73 & 11.44 & 10.51 & 11.07 & 8.12 & 5.66 & 6.63 \\
\hline Commercial landings (mil. lbs) & 10.04 & 9.21 & 10.94 & 13.04 & 16.56 & 13.03 & 12.49 & 11.07 & 10.68 & 7.81 & - & - \\
\hline$\%$ of commercial quota landed & $103 \%$ & $99 \%$ & $102 \%$ & $102 \%$ & $95 \%$ & $102 \%$ & $109 \%$ & $105 \%$ & $96 \%$ & $96 \%$ & - & - \\
\hline Recreational ACL (mil. lbs) & - & - & - & - & - & 11.58 & 10.23 & 9.07 & 9.44 & 6.83 & 4.72 & 5.53 \\
\hline Recreational harvest limit (mil. lbs) $)^{b}$ & 6.68 & 6.21 & 7.16 & 8.59 & 11.58 & 8.49 & 7.63 & 7.01 & 7.38 & 5.42 & 3.77 & 4.42 \\
\hline Recreational landings (mil. lb) & 9.34 & 8.15 & 6.03 & 5.11 & 5.96 & 6.49 & 7.36 & 7.39 & 4.72 & 6.18 & - & - \\
\hline$\%$ of recreational harvest limit landed & $140 \%$ & $131 \%$ & $84 \%$ & $59 \%$ & $51 \%$ & $76 \%$ & $97 \%$ & $105 \%$ & $64 \%$ & $114 \%$ & - & - \\
\hline
\end{tabular}

Note: Based on the Mid-Atlantic Fishery Management Council Summer Flounder Fishery Information Document from June 2017.

${ }^{a}$ The ABC is the annual Acceptable Biological Catch for the entire summer flounder fishery, and is divided into sector-specific Annual Catch Limits (ACLs) for the commercial and recreational fisheries. The ABC and ACLs include both landings and discards.

${ }^{b}$ Commercial quotas and recreational harvest limits reflect the removal of projected discards from the sectorspecific ACLs. For 2006-2014, these limits are also adjusted for Research Set Aside (RSA). Quotas and harvest limits for 2015-2016 do not reflect an adjustment for RSA due to the suspension of the program in 2014.

${ }^{c}$ Currently implemented; subject to change based on SSC review and subsequent Council and Commission review.

\section{Methods}

\subsection{Management Strategy Evaluation}

The simulation model used for this analysis is a modification of the management strategy evaluation (MSE) model developed by Wiedenmann et al. (2017), who evaluated harvest control rule performance for species with generic life history strategies (short-, medium- and long-lived). The current model is parameterized specifically for summer flounder using information from the 2015 stock assessment (Terceiro 2015). Full details of the model and parameters used can be found in the Appendix A, but a brief description of the model is provided here. The model is a closed-loop simulation (Butterworth and Punt 1999) developed in AD Model Builder (Fournier et al. 2012), split into two periods. The historical period covers $1982-2014$, as this is the period where we have estimates of both population size and fishery catches from the stock assessment (Terceiro 2015). During the historical period, the population and fishery dynamics for summer flounder are fixed based on the assessment estimates. The future period spans 2015-2040, and both population and fishery dynamics vary across model iterations. Variability in the future summer flounder population dynamics occurs through stochastic annual recruitment to the population, through random, time-varying adult natural mortality $(M)$, and through the annual fishing mortality rate $(F)$. The annual $F$ in the future period is determined by the annual fishery catches and the population size that year. Annual catches are determined from multiyear projections based on statistical catch at age (SCAA) stock assessments (Fournier and Archibald 1982) that are done throughout the future period, fit to data generated in both the historical and future periods (see Appendix A for more details on the population, data-generating, and assessment dynamics). Estimated abundance of summer flounder in the final year of the stock assessment is projected forward with future fishing mortality set at the estimated FMSY, producing annual estimates of the catch that defines overfishing (the overfishing limit, or OFL). The current MAFMC control rule is then used to estimate the $\mathrm{ABC}$ by applying a buffer to OFL, with the size of the buffer dependent on the estimated biomass relative to the target biomass. The $\mathrm{ABC}$ in a given year is assumed to be removed from the population with no implementation uncertainty (i.e., actual catch $=\mathrm{ABC}$ ), and the assessment and $\mathrm{ABC}$-setting processes are repeated the specified number of times throughout the future period, depending on the updating frequency scenario being explored. As can be seen in table 1, there have been exceedances 
and under harvest for both commercial and recreational fishing, with the issue being more prominent in the recreational fishery.

The number of assessments conducted throughout the management period is determined by the specified number of years between them (herein called the assessment interval), with longer assessment intervals resulting in fewer stock assessments being done in the future period. The assessment interval also determines the number of years that the $\mathrm{ABC}$ must be set using projections. We explored stock assessment intervals of 1, 2, 3 and 5 years. Assessments in our model done in year $t$ have a specified amount of data lag, where the final year in the assessment is earlier than the current assessment year. We explored data lags of 1 and 2 years, which resulted in the final year in each assessment being out of date by the specified amount of lag (i.e, assessment estimates through year $\mathrm{t}-1$, or $\mathrm{t}-2$ for data lags of 1 or 2 years, respectively). The net effect of the data-lag and assessment interval is that ABCs set over a longer interval and with the larger data lag are based on increasingly out of date information. We explored the range of assessment intervals and data lags in a factorial manner for a total of 8 runs, with 100 iterations for each interval-lag combination. Annual estimates of the true population biomass and yield to the fishery (both in total weight and in numbers caught at age) from each run are stored for use in the economic model, described below.

\subsubsection{Biological model results}

Results are calibrated to reflect past summer flounder stock dynamics. Figure 2 shows the model fit (dots up to year 2014) to the past SSB and catch time series (line) together with the range of the baseline simulation results (dots from 2015 to 2040).

Fig. 2. Model fit and simulation over time for the baseline data scenario.
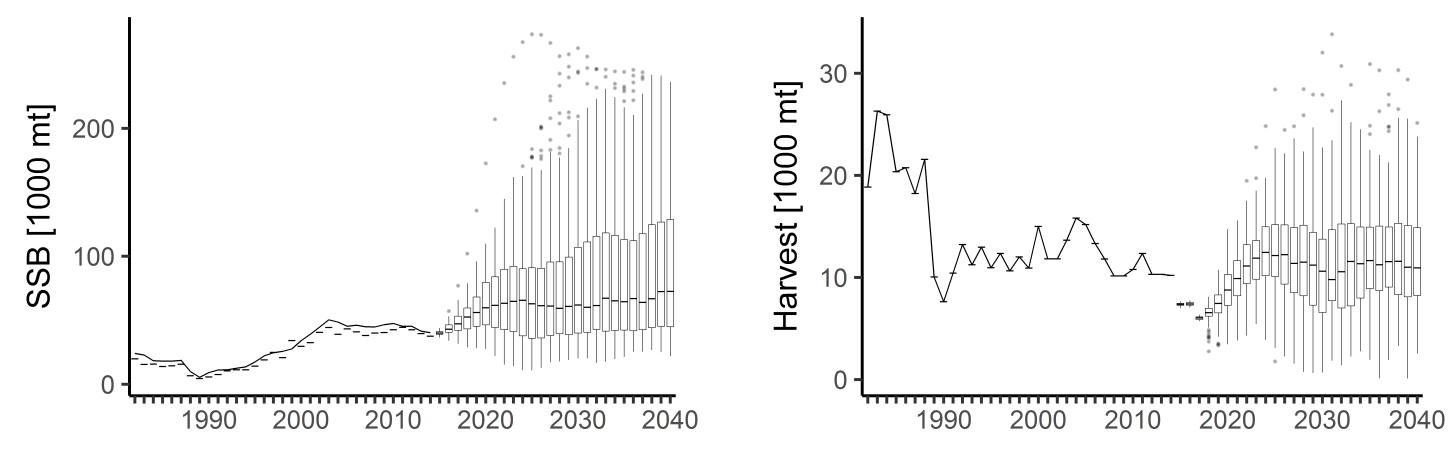

\subsection{Economic submodel for summer flounder}

Our motivation for the economic models that follow is that predictions of future TACs and SSB for summer flounder can be made more valuable to the decision maker if they are translated to net economic values. Catches can be converted to revenues, but one has to determine what price to multiply harvests by. Since price fluctuates with harvest levels, we develop a model of demand for summer flounder. The demand adjusted prices provide projections of gross revenues, but do not take into account changing fishing costs. A model of fishing costs that adjusts due to changes in the TAC as well as SSB is developed, and that allows us to calculate net revenue changes as an indicator of producer welfare. We also use the demand model to estimate downstream and consumer benefits from changing summer flounder harvests and prices. Finally, because recreational fishing is a non-market activity, we 
Hutniczak et al.

estimate a random utility model that uses summer flounder catch rates and angler travel costs to determine changes in net economic benefits to recreational fishermen. The SSB impacts the catch rates in the model, and this interacts with the change in the recreational quota to impact the amount of recreational fishing, and thus, its aggregate value. The net present value of economic impacts on these three groups (i.e., consumers, recreational and commercial fishermen) is added together to provide an aggregate impact of the benefits for each of the scenarios analyzed.

\subsection{Market Demand for summer flounder}

\subsubsection{Model of demand}

Regulations restricting the total allowable catch generate a movement along the inverse demand curve (i.e., price is a function of quantity) for the species and a corresponding change in consumer valuation (and quasi-rents to fish processors) (Park et al. 2004). Accounting for the change in price due to annual changes in the TAC has two implications for our analysis of the value of stock assessment frequency and data management lag. One is that the change in price implies a change in consumer surplus that should be taken into account in any recommendation regarding frequency and lag. Similarly, the change in price will impact producer surplus estimated later on in the analysis.

For estimation of price flexibilities (ratio of percentage change in price for a percentage change in quantity), we use the Synthetic Inverse Demand System (SIDS) (Brown et al. 1995, Eales et al. 1997), which is standard practice in fisheries due to the exogeneity of catch as being pre-determined by both biology and management (Lee and Thunberg 2013). ${ }^{2}$ SIDS is the most general model that nests other widely-used models: inverse Rotterdam (IROT), inverse Almost Ideal Demand System (IAIDS), inverse Central Bureau of Statistics (ICBS) and inverse National Bureau of Research (INBR) models. SIDSs estimable form is:

$w_{i t} \Delta \ln v_{i t}=\alpha_{i}+\sum_{j} \pi_{i j} \Delta \ln q_{j t}+\pi_{i} \Delta \ln Q_{t}-\theta_{1} w_{i t} \Delta \ln Q_{t}-\theta_{2} w_{i t} \Delta \ln \left(q_{i t} / Q_{t}\right)+\varepsilon_{i t}$

where $i, j(i, j \in I)$ index goods, $t \in T$ indicates time, $\Delta$ indicates difference with respect to $t-1$ of the following variable, $w_{i t}$ are expenditure shares, $v_{i t}$ are prices normalized by total expenditure $\left(v_{i t}=p_{i t} / \sum_{i} p_{i t} q_{i t}, p_{i t}\right.$ is market price and $q_{i t}$ is quantity supplied), $\ln Q_{t}$ is price index such that $\ln Q_{t}=\sum_{i} w_{i t} \ln q_{i t}, \theta_{1}$ and $\theta_{2}$ are mixing parameters $\left(\theta_{1}, \theta_{2} \in[0,1]\right)$. Parameters $\theta_{1}$ and $\theta_{2}$ simplify the SIDS model to IROT if $\theta_{1}=0$ and $\theta_{2}=0$, IAIDS if $\theta_{1}=1$ and $\theta_{2}=1$, ICBS if $\theta_{1}=1$ and $\theta_{2}=0$, INBR if $\theta_{1}=0$ and $\theta_{2}=1$. The constraints required for SIDS to be consistent with demand theory include symmetry: $\pi_{i j}=\pi_{j i}$, adding up $\sum_{i} \pi_{i j}=0$ and $\sum_{i}\left(\pi_{i}\right)-\theta_{1}+1=0$, homogeneity $\sum_{j} \pi_{i j}=0$, and $\sum_{i} \alpha_{i}=0$. The compensated cross-price flexibilities are:

$f_{i j}^{*}=\pi_{i j} / w_{i}+\theta_{2} w_{j}$

The compensated own-price flexibilities are:

$f_{i i}^{*}=\pi_{i i} / w_{i}-\theta_{2}+\theta_{2} w_{i}$

\footnotetext{
${ }^{2}$ As noted by Lee and Thunberg (2013), "Inverse demand models have frequently been used in modeling demand for fish and other perishables. Use of an inverse, instead of direct demand model is typically justified on two grounds. First, the supply of fish is inelastic in the short-run; therefore, quantities, not prices, are pre-determined when trade occurs in the market. Second, the fisheries management policy that motivates the investigation of demand typically sets quantities, not prices."
} 
The welfare effects to consumers and fish processors on shore are measured as changes in derived demand surplus measures and approximated as the area below the inverse demand curve using (Park et al. 2004):

$Q C V_{i}\left(t=t_{0} \rightarrow t=t_{1}\right)=\left(-\Delta q_{i}\right)\left(v_{i t_{0}}+0.5\left[f_{i i}^{*} v_{i t_{0}} / q_{i t_{0}}\right] \Delta q_{i}\right)$

\subsubsection{Demand data}

We estimate the SIDS model for five group of products supplied to the east coast of the US from Massachusetts to North Carolina. Summer flounder alone constitutes the first group. The second group includes domestic harvest of other flatfish, including: fourspot flounder, southern flounder, yellowtail flounder, windowpane flounder, winter flounder, witch flounder, plaice, and halibut. The third group includes large mesh caught groundfish: cod, haddock, hake, pollock, and redfish. The remaining two groups include flatfish and groundfish imports to US east coast ports.

The data on imports includes only products for consumption and excludes products highly processed or of considerably different use (e.g. canned fish, roe, surimi and large frozen blocks). Quantities are per 1000 residents of the east coast. We use annual quantity and value landings and import data from NOAA Fisheries Statistics Division from 1990-2014. All prices are adjusted to 2014 USD using the producer price index for unprocessed and packaged fish from the US Bureau of Labor Statistics. The summary of demand data is available in table 2 .

Table 2. Demand data summary (annual).

\begin{tabular}{l|rrrr}
\hline Variable & Mean & STD & Min & Max \\
\hline Summer flounder landings & 174.7 & 37.2 & 117.2 & 243.4 \\
Other flatfish landings & 395.7 & 188.6 & 165.1 & 839.4 \\
Groundfish landings & 979.6 & 385.0 & 524.7 & 2215.4 \\
Flatfish imports & 407.1 & 81.2 & 273.0 & 564.7 \\
Groundfish imports & 2071.7 & 458.4 & 1030.0 & 2795.8 \\
Summer flounder price & 2.76 & 0.33 & 2.12 & 3.60 \\
Other flatfish price & 2.07 & 0.34 & 1.48 & 2.59 \\
Groundfish price & 1.16 & 0.11 & 0.88 & 1.34 \\
Flatfish imports price & 3.51 & 0.81 & 2.49 & 4.84 \\
Groundfish imports price & 2.98 & 0.56 & 2.22 & 4.28 \\
\hline
\end{tabular}

Note: Landings in lbs per year per 1000 of the EC residents. Other flatfish and groundfish landings include only the EC fisheries. Imports to the EC only, in lbs per 1000 of the EC residents. Prices calculated as average price per $\mathrm{lb}$ in 2014 USD.

\subsubsection{Demand model results}

Inverse demand is based on 25 annual observations ( 24 effectively because of one period lag). The stationarity of final regression variables (after mathematical transformations indicated by the inverse demand model formula) is tested using the Dickey-Fuller test (Dickey and Fuller 1979). The unit root is rejected for all variables included in the demand model. The model is estimated as a system of equations, dropping one of them to avoid singularity, and using generalized method of moments (GMM). We use heteroscedasticity and serial correlation robust standard errors (Newey and West 1987) with an optimal lag-selection algorithm (Newey and West 1994). The Newey optimal lag-selection algorithm resulted in 14 period lag for the error term. The final model has 20 estimated parameters and 7 derived from model restrictions. The model is tested to determine the validity of the overidentifying 
Hutniczak et al.

restrictions through Hansens $\mathbf{J}$ statistic with a null hypothesis of a correct model specification and valid overidentifying restrictions (Hansen 1982). Hansens J statistics - $\chi^{2}=2.17(p=0.704)$ implies valid overidentifying restrictions and that the model satisfies the required orthogonality conditions and is correctly specified. The following nested model were rejected: IROT ( $\left.\chi^{2}=51.92, p=0.000\right)$, IAIDS $\left(\chi^{2}=56.13, p=0.000\right)$, INBR $\left(\chi^{2}=226.73, p=0.000\right)$, but results suggest that the model could be simplified to ICBS $\left(\chi^{2}=1.53, p=0.465\right)$ The estimation results are available in the Appendix B. Compensated price flexibilities used in evaluation of welfare effects are presented in table 3 .

The demand model results in estimated prices that adjust according to the price flexibility as sum-

Table 3. Compensated price flexibilities.

\begin{tabular}{cccccc}
\hline & $\begin{array}{c}\text { Summer flounder } \\
\text { - domestic }(\mathrm{G} 1)\end{array}$ & $\begin{array}{c}\text { Other flatfish } \\
\text { - domestic }(\mathrm{G} 2)\end{array}$ & $\begin{array}{c}\text { Groundfish } \\
\text { - domestic }(\mathrm{G} 3)\end{array}$ & $\begin{array}{c}\text { Flatfish } \\
\text { import (G4) }\end{array}$ & $\begin{array}{c}\text { Groundfish } \\
\text { import (G5) }\end{array}$ \\
\hline G1 & -0.352 & -0.256 & 0.228 & -0.065 & 0.446 \\
& $(0.047)$ & $(0.031)$ & $(0.028)$ & $(0.066)$ & $(0.095)$ \\
G2 & -0.150 & -0.396 & -0.076 & 0.075 & 0.547 \\
& $(0.018)$ & $(0.047)$ & $(0.042)$ & $(0.030)$ & $(0.034)$ \\
G3 & 0.096 & -0.054 & -0.032 & -0.137 & 0.128 \\
& $(0.012)$ & $(0.030)$ & $(0.025)$ & $(0.030)$ & $(0.042)$ \\
G4 & -0.022 & 0.044 & -0.112 & -0.205 & 0.296 \\
& $(0.023)$ & $(0.018)$ & $(0.024)$ & $(0.019)$ & $(0.065)$ \\
G5 & 0.036 & 0.075 & 0.024 & 0.069 & -0.204 \\
& $(0.008)$ & $(0.005)$ & $(0.008)$ & $(0.015)$ & $(0.031)$ \\
\hline
\end{tabular}

Note: Evaluated at mean quantities and prices. Standard errors in parentheses; not significant $(p>0.05)$ in italics.

mer flounder commercial harvests change over time. Harvests of all other species groups are held constant at their average level. This affects both consumer surplus and commercial sector profits (section 4.4.1) For the demand model simulation, we assume an east coast US population growth rate of $0.6 \%$, corresponding to the average growth rate since 2000 . We apply a $3 \%$ discount rate to the model and subsequent calculations, as is common practice in US fisheries management regulatory analyses NOAA (1999).

\subsubsection{Demand driven welfare effects}

Consumer welfare effects are calculated in terms of the change from estimated catch volume to a zero catch for each time period in each model run, resulting in a total value of the resource to East Coast consumers. Then the average over the simulation period was calculated for each model run. Figure 3 presents the distribution of differences between the base scenario ( $S A$ interval $=1$ and $\mathrm{DML}=2$ ) and each alternative scenario classified by SA interval and DML for each iteration of the biological model.

\subsection{Commercial production}

\subsubsection{Model of commercial fishery}

We use data on otter trawling for east coast states from Massachusetts to North Carolina since it is the predominant method and region for harvesting summer flounder. This is a complex, multispecies fishery that is challenging to structurally model in a theoretically consistent manner (Kirkley 
Can. J. Fish. Aquat. Sci.

Fig. 3. Distribution of estimated consumer welfare effects showing median value of differences in yearly average effect over the simulation period between the baseline scenario and alternative SA interval and DML.

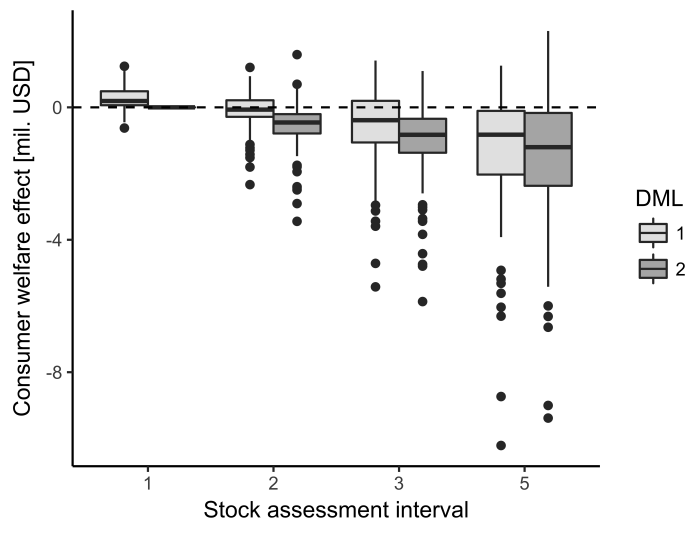

and Strand 1988). ${ }^{3}$ To make this empirically tractable, harvest is divided into five species groups: 1) summer flounder (SF), 2) other bottom fish (FL) (American plaice, fourspot flounder, sand-dab, winter flounder, witch flounder, yellowtail flounder, halibut, cod, haddock, hake, pollock and redfish), 3) baitfish (BF) (menhaden, herring, butterfish, mackerel, skate), 4) shellfish (SH) (shrimp, squid, lobster, scallop and other mussels) and 5) other species (OT).

The empirical model is specified in an additively separable reduced form as a first-difference equation explaining the change in the effort required to harvest a different TAC.

$\Delta D_{n t}=\beta_{0}+\sum_{i \in I} \Delta y_{i n t}\left(\beta_{i}+\beta_{k i} k_{n}+\beta_{b i} b_{i t}+\beta_{s i} S T_{n t}\right)+\epsilon_{n t}$

Here $\Delta D_{n t}$ is year to year change in number of days vessel $n$ spends at sea (e.i. $D_{n t}-D_{n t-1}$ ), $\Delta y_{\text {int }}$ are year to year changes in landings of species $i(i \in I=\{S F, F L, B F, S H, O T\}), k_{n}$ are quasi-fixed input in form of capital approximated with tonnage of vessel $n, b_{i t}$ is biomass of species $i$ at time $t$ that is replaced with time dummies for species without available biomass estimates, $S T_{n t}$ are dummies for homeport state and $\epsilon_{n t}$ is the error term.

Producer net revenues are calculated as a difference between derived revenues and trip costs. Total revenues are calculated by assuming the harvest control rule derived quota is binding, and multiplying by the price estimated from the demand model. Costs are calculated based on the total days necessary to harvest given catch (equation 5) multiplied by effort unit cost per day.

\subsubsection{Supply data}

The data used in change of days at sea analysis is summarized in table 4 . The summary is based on 8699 annual observations from fishing Vessel Trip Reports (VTR) from 1996 to 2014, focusing on

\footnotetext{
${ }^{3}$ A reviewer suggested that a fully specified structural model of this fishery that estimates a multi-product cost or profit function would capture the jointness in production and allow for more robust modeling. This would be particularly desirable in a multi-species management framework where we were looking at not only changes in summer flounder, but in changes in quotas and biomass of the other species as well.
} 
Hutniczak et al.

vessels with summer flounder harvest permit. The trip cost is based on values derived from parameters estimated by Jin et al. (2016). Values are based on trip characteristics and are adjusted for sampling bias. We add labor cost based on average captain and crew rates, and reported number of days at sea. The data only cover operating costs. The cost mean is based on 2065 values derived for 2009-2014, following the time span in original model by Jin et al. (2016). For welfare estimates, we only used results reflecting 2014 .

Table 4. Fleet data summary.

\begin{tabular}{lrrrr}
\hline Variable & Mean & SD & Min & Max \\
\hline Days at sea (calendar) - D & 113 & 74 & 1 & 421 \\
Landings of summer flounder [lbs]- $y_{S F}$ & 22870 & 32018 & 0 & 272450 \\
Landings of other bottom fish [lbs]- $y_{F L}$ & 93665 & 146013 & 0 & 1727766 \\
Landings of bait fish [lbs] - $y_{B F}$ & 67165 & 342075 & 0 & 9140000 \\
Landings of shellfish [lbs] - $y_{S H}$ & 110389 & 486507 & 0 & 9896700 \\
Landings of other fish species [lbs] - yOT & 66928 & 212721 & 0 & 3599206 \\
Vessel tonnage [Gt] - $k$ & 96 & 51 & 1 & 201 \\
Biomass index for summer flounder - $b_{S F}$ & 0.962 & 0.195 & 0.690 & 1.337 \\
Cost [2014 USD] & 97526 & 106456 & 273 & 765722 \\
\hline
\end{tabular}

\subsubsection{Supply model results}

Results of the supply model are presented in table 5. The equation has $R^{2}=0.48$ based on 7497 available observations (effectively because of one period lag). Breusch-Pagan test rejects heteroskedasticity $\left(\chi^{2}=1.22, p=0.27\right)$.

Summer flounder biomass affects the number of days spent fishing and thus affects the profit through

Table 5. Effort first-difference regression results.

\begin{tabular}{cccc}
\hline Coefficient & Estimate & SE & $\mathrm{p}$ \\
\hline$\beta_{0}$ & -2.596362 & 0.3976911 & 0 \\
$\beta_{S F}$ & 0.001880 & 0.000277 & 0 \\
$\beta_{F L}$ & 0.000504 & 0.000060 & 0 \\
$\beta_{B F}$ & 0.000022 & 0.000032 & 0.502 \\
$\beta_{S H}$ & 0.000284 & 0.000040 & 0 \\
$\beta_{O T}$ & 0.000148 & 0.000025 & 0 \\
\hline$\beta_{k S F}$ & -0.000006 & 0.000001 & 0 \\
$\beta_{k F L}$ & -0.000002 & 0.000000 & 0 \\
$\beta_{k B T}$ & 0.000000 & 0.000000 & 0 \\
$\beta_{k S H}$ & -0.000001 & 0.000000 & 0 \\
$\beta_{k O T}$ & 0.000000 & 0.000000 & 0.001 \\
\hline$\beta_{b S F}$ & -0.000406 & 0.000115 & 0 \\
\hline
\end{tabular}

Note: Coefficients for time and state dummies omitted.

its impact on harvest cost. The final values are scaled to reflect the whole fishery, i.e. the calculated values are multiplied by a factor representing inverse of $\%$ of the total catch covered by VTR data used in the model $(74.8 \%)$. The results representing differences in mean values over the simulation period in comparison with the baseline scenario median (SA interval=1, DML=2) are presented in figure 4. 
Can. J. Fish. Aquat. Sci.

Fig. 4. Distribution of estimated commercial producer welfare effects showing median value of differences in yearly average effect over the simulation period between the baseline scenario and alternative SA interval and DML.

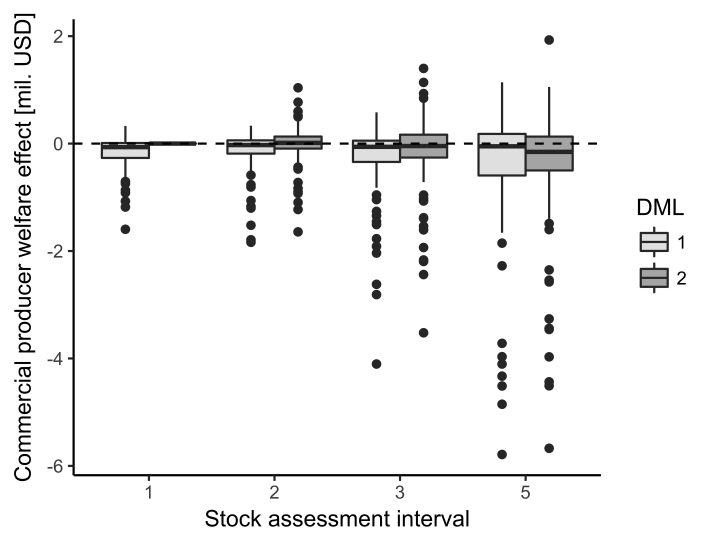

\subsection{Recreational fishery}

\subsubsection{Model of recreational fishing}

The model considers a two level choice where willingness to pay for a recreational trip is estimated using a nested logit model. Included in the choice set along with summer flounder, we use the Mcconnell and Strand (1994) target species groups of small game fish (striped bass, bluefish, mackerel, seatrout, red drum and Atlantic bonito), and bottom fish (tautog, scup, black sea bass, Atlantic cod, kingfish, sheepshead, white perch and black drum). We consider choice of fishing mode: shore (SH), private and rental (PR), party and charter (HD), and fishing site aggregated to the county level (Gentner et al. 2010, Hicks and Schnier 2016). The first level choice is a simultaneous decision on target species and mode ( $3 \times 3=9$ nests) and the second level choice as a decision on fishing location ( 88 alternatives). The random utility model (RUM), (Haab and Mcconnell 2003) assumes that individual angler $i$ chooses alternative that gives the highest utility, that is utility $U_{s^{*}, m^{*}, l^{*}}^{i}>U_{s, m, l}^{i} \forall s \in S, m \in M, l \in L^{i}$ where $s$ indicates species group from set $S, m$ indicates fishing mode from set $M$ and $l$ indicates location from set of all locations available to angler $i, L^{i}$. The indirect utility is defined as $U_{s, m, l}^{i}=v_{s, m, l}^{i}+\epsilon_{s, m, l}^{i}=$ $\mathbf{x}_{\mathbf{s}, \mathbf{m}, \mathbf{l}}^{\mathbf{i}} \beta+\epsilon_{s, m, l}^{i}$, where $v_{s, m, l}^{i}$ is a deterministic component of utility, $\mathbf{x}_{\mathbf{s}, \mathbf{m}, \mathbf{l}}^{\mathbf{i}}$ is a vector of explanatory variables, $\beta$ is a vector of coefficients to estimate, and $\epsilon_{s, m, l}^{i}$ is a random component of preferences. The $v_{s, m, l}^{i}$ component is specified as:

$$
\begin{aligned}
v_{s, m, l}^{i}= & \beta_{\text {cost }} \operatorname{cost}_{l}^{i}+\sum_{s \in S} \beta_{s} c_{s, m, l} d_{s}+ \\
& \sum_{m \in M} \beta_{m} d_{m}+\beta_{n s} \ln \left(n s_{l}\right)
\end{aligned}
$$

where $\operatorname{cost}_{l}^{i}$ is individual angler's cost of trip to location $l, c_{s, m, l}$ indicate catch rates for target species, $d_{s}$ are target species dummies, $s=\mathrm{SF}$ for summer flounder, $s=\mathrm{SG}$ for small game fish and $s=\mathrm{BT}$ for bottom fish for given trip profile respectively, and $n s_{l}$ is location adjustment factor indicating number of fishing sites in county $l$.

The probability of choice $s^{*}, m^{*}, l^{*}$, given the equation 6 , is: 
Hutniczak et al.

$P\left(d_{s^{*}, m^{*}, l^{*}}^{i} \mid \beta, \mathbf{X}^{\mathbf{i}}\right)=\frac{\exp \left(v_{s^{*}, m^{*}, l^{*}}^{i} / \theta_{s^{*}, m^{*}}\right)\left[\sum_{l \in L^{i}} \exp \left(v_{s^{*}, m^{*}, l}^{i} / \theta_{s^{*}, m^{*}}\right)\right]^{\theta_{s^{*}, m^{*}}}}{\sum_{l \in L^{i}} \exp \left(v_{s^{*}, m^{*}, l}^{i} / \theta_{s^{*}, m^{*}}\right) \sum_{s \in S} \sum_{m \in M}\left[\sum_{l \in L^{i}} \exp \left(v_{s, m, l}^{i}\right)\right]^{\theta_{s, m}}}$

where $d_{s^{*}, m^{*}, l^{*}}^{i}$ is choice indicator, 1 if alternative was chosen and 0 if not, and $\theta_{s, m}$ are nest specific dissimilarity parameters estimated with nested logit model.

The expected catch rates for each alternative are estimated by fitting a two-part model for mixedcontinuous outcomes (Belotti et al. 2015). The binary component of observing a positive versus zero outcome is fitted with a logistic regression. Then, conditional on positive outcome, the number of fish caught is fitted with a generalized linear model with the log link and gamma distribution. The full specification of the model is as follows:

$$
\begin{aligned}
& c_{s, m, l}^{i}= \alpha_{b} \ln \left(b_{s}^{i}\right)+\alpha_{h} \ln \left(h r_{s, m, l}^{i}\right)+\alpha_{e} \exp p_{s, m, l}^{i}+ \\
& \sum_{w \in[1,6]} \sum_{l \in L} \alpha_{w, l} d_{\text {wave }}^{i} d_{l}^{i}+\sum_{m \in M} \alpha_{m} d_{m}^{i} \\
& \text { for s=SF and year } \in(2004,2014) \\
& c_{s, m, l}^{i}= \alpha_{h} \ln \left(h r_{s, m, l}^{i}\right)+\alpha_{e} \exp p_{s, m, l}^{i}+ \\
& \sum_{w \in[1,6]} \sum_{l \in L} \alpha_{w, l} d_{\text {wave }}^{i} d_{l}^{i}+\sum_{m \in M} \alpha_{m} d_{m}^{i} \\
& \text { for s }=(\mathrm{SG}, \mathrm{BT}) \text { and year }=2014
\end{aligned}
$$

where $b_{s}^{i}$ is a yearly biomass indicator for summer flounder (SF) that is assigned to each fishing occasion, given available stock assessment estimates and normalized to 1 for base year (2014), $h r_{s, m, l}^{i}$ is angling effort in hours of fishing, $\exp _{s, m, l}^{i}$ is experience indicator, given by number of fishing trips in the past year including the surveyed trip, $d_{\text {wave }}^{i}$ is wave dummy, $d_{l}^{i}$ is site dummy (defined the same way as in equation 6), and $d_{m}^{i}$ is a fishing mode dummy. The site quality used in the RUM model (equation 6) of catch rate per hour fished for each available $s, m, l$ combination, is standardized to $h r=1$ and $\exp =1$. The full estimation results are available in the Appendix C. The small game species and bottom fish are estimated using only 2014 data without using biomass that is unavailable for an aggregated group of species. We use changes in biomass of summer flounder from the simulation model to estimate new expected catch rates and consequently, using the RUM model, the welfare effects. The welfare effects in form of compensating variation (CV) per trip is defined for individual $i$ as:

$$
C V\left(\mathbf{x}_{\mathbf{s}, \mathbf{m}, \mathbf{l}}^{\mathbf{i}, \mathbf{0}} \rightarrow \mathbf{x}_{\mathbf{s}, \mathbf{m}, \mathbf{1}}^{\mathbf{i}, \mathbf{1}}\right)=\beta_{\text {cost }}^{-1} \ln \frac{\sum_{s \in S} \sum_{m \in M}\left[\sum_{l \in L_{i}} \exp \left(\mathbf{x}_{\mathbf{s}, \mathbf{m}, \mathbf{1}}^{\mathbf{i}, \mathbf{0}} \beta / \theta_{s, m}\right)\right]^{\theta_{s, m}}}{\sum_{s \in S} \sum_{m \in M}\left[\sum_{l \in L_{i}} \exp \left(\mathbf{x}_{\mathbf{s}, \mathbf{m}, \mathbf{1}}^{\mathbf{i}, \mathbf{1}} \beta / \theta_{\mathbf{s}, \mathbf{m}}\right)\right]^{\theta_{s, m}}}
$$

where $\mathrm{x}_{\mathbf{s}, \mathbf{m}, \mathbf{1}}^{\mathrm{i}, \mathbf{0}} \rightarrow \mathrm{x}_{\mathbf{s}, \mathbf{m}, \mathbf{1}}^{\mathrm{i}, \mathbf{1}}$ represents a change in vector of attributes for each alternative from values observed in 2014 to values derived from each evaluated scenario. The total welfare change is estimated as follows. For each biomass change, the new expected catch rates and the CV for each trip are calculated. The $\mathrm{CV}$ for each trip is then multiplied by its sampling weight that represents the number of trips the given observation represents and summed over all trips. The relative change of the sum of catch rates between the reference and simulated scenario provides the number of trips required to harvest the 
original catch limit. We calculate the share $(s h)$ of original trips that would be needed to harvest the new catch limit. This share is used to scale the sum of CV - this represents a compensating variation for share of trips allowed to harvest summer flounder under the new fishing conditions up to the catch limit. If the number of trips allowed to fish summer flounder is lower than the reference year $(s h<1)$, we calculate the value lost due to elimination of the summer flounder option (summer flounder catch rates driven to zero) for each surveyed trip in the reference year. We then multiply the welfare loss for each trip by the survey weight, sum it and scale by $(1-s h)$, the share of original trips that under new conditions would not be allowed to harvest summer flounder. In the case of $s h>1$, we assume that additional trips with new catch rates can be introduced. Then $\mathrm{CV}$ is the sum of the value added due to change in expected catch rate and the value gained through adding additional trips.

\subsubsection{Recreational data}

For estimating the recreational model, we use data collected from the Marine Recreational Information Program (MRIP) survey conducted by the National Marine Fisheries Service in 2014. We use trips occurring from North Carolina to Massachusetts, using hook and line, happening not earlier than March (due to limited observations in January-February sampling wave) and targeting species included in groups defined earlier. The summary of data used to calculate expected catch rates is available in table 6.

There are 18377 trips and over 14 million alternatives to evaluate. Following past studies (Mcconnell and Strand 1994, Hicks and Schnier 2016), we reduce the choice set to alternatives with a one way distance of angler travel of less than 150 miles. This leaves about 3.3 million alternatives. We use NOAA Fisheries estimated distances and to calculate costs use a federal reimbursement rate of USD 0.56 per mile. Since we do not consider the opportunity cost of time in our model (Gentner et al. 2010), the results should be considered a lower-bound estimate (Hicks and Schnier 2016).

Table 6. Recreational data summary - used for two part model.

\begin{tabular}{lrrrr}
\hline Variable & Mean & SD & Min & Max \\
\hline Summer flounder (SF): 2004-2014 & & & & \\
\hline Catch rate c & 3.274 & 5.094 & 0 & 111 \\
Hours of fishing hr & 4.059 & 1.648 & 0.5 & 14 \\
Experience - exp & 23.898 & 34.688 & 1 & 365 \\
Biomass [mt] & 45026 & 2348 & 40323 & 48549 \\
\hline Small game fish (SG): 2014 & & & & \\
\hline Catch rate c & 2.773 & 6.999 & 0 & 489 \\
Hours of fishing hr & 4.051 & 1.905 & 0.5 & 14 \\
Experience - exp & 31.072 & 45.649 & 1 & 365 \\
\hline Other bottom fish (BT): 2014 & & & & \\
\hline Catch rate c & 8.916 & 14.790 & 0 & 237 \\
Hours of fishing hr & 4.318 & 1.770 & 0.5 & 14 \\
Experience - exp & 26.194 & 39.488 & 1 & 365 \\
\hline
\end{tabular}

\subsubsection{Recreational model results}

The evaluation of recreational harvest starts with estimation of expected catch rates in number of fish per hour of fishing activity. We predict the catch rate for each site available in the MRIP data set, separately for trips grouped according to the targeted species group, location and wave. The predicted values were then averaged for each county included in the choice set. 
Hutniczak et al.

Using the predicted expected catch rates, we estimate the nested logit model where nests define a simultaneous choice of target species and mode. The results are available in table 7. The Wald $\chi^{2}$ of 5044.5 with a p-value $=0.000$ tells us that our model as a whole fits significantly better than an empty model (i.e., a model with no predictors). The significant difference of dissimilarity parameters $\left(\chi^{2}=\right.$ 2442.9 , p-value $=0.000$ ) suggest that the model would be misspecified if nests were not distinguished. Figure 5 shows general results for relative changes in biomass and catch, whereas figure 6 shows the results for the simulation model.

Table 7. Nested logit results for recreational harvest.

\begin{tabular}{cccc}
\hline Coefficient & Estimate & $\mathrm{SE}$ & $\mathrm{p}$ \\
\hline$\gamma_{\text {cost }}$ & -0.084 & 0.003 & 0.000 \\
$\gamma_{S F}$ & 3.261 & 0.063 & 0.000 \\
$\gamma_{S G}$ & 1.726 & 0.038 & 0.000 \\
$\gamma_{B T}$ & 0.479 & 0.020 & 0.000 \\
$\gamma_{H D}$ & -1.269 & 0.064 & 0.000 \\
$\gamma_{P R}$ & 0.712 & 0.041 & 0.000 \\
$\gamma_{n s}$ & 3.209 & 0.107 & 0.000 \\
\hline Dissimilarity parameters & & & \\
\hline$\tau_{S F, S H}$ & 1.593 & 0.064 & \\
$\tau_{S F, H D}$ & 2.381 & 0.077 & \\
$\tau_{S F, P R}$ & 1.756 & 0.063 & \\
$\tau_{S G, S H}$ & 2.060 & 0.063 & \\
$\tau_{S G, H D}$ & 2.239 & 0.071 & \\
$\tau_{S G, P R}$ & 2.026 & 0.062 & \\
$\tau_{B T, S H}$ & 1.614 & 0.060 & \\
$\tau_{B T, H D}$ & 2.520 & 0.073 & \\
$\tau_{B T, P R}$ & 1.434 & 0.058 & \\
\hline
\end{tabular}

Note: LR test for IIA $(\tau=1): \chi^{2}(9)=2442.9, p>\chi^{2}=0.000$.

\subsection{Comparison of Scenarios}

Table 8 provides a summary of the median differences in scenarios for the average annual producer net revenue, consumer compensating variation and recreational compensating variation for 8 scenarios, combining 1, 2, 3 and 5 year stock assessment update intervals with one or two year data management lags. Additionally, the last column provides the total aggregate welfare effects for the median values from the scenario runs. Our baseline scenario of a one year updating interval with a two year data management lag had a total welfare effect of USD 2.43 billion (figure 7).

We compare the results of the different scenarios compared with the baseline, but note that they are not statistically significantly different from each other. Despite this lack of significance, there are some interesting trends that we highlight here. First, as expected, the more frequent updating and reduced data lag resulted in higher aggregate welfare. However, on a sector by sector basis, the impact was not consistent. Commercial fishermen were slightly worse off when the data management lag was reduced from two to one year when the stock assessment was updated yearly. The same held when the stock assessment was updated every two years. Similarly, with a one year data lag, the two year stock assessment update slightly outperformed the one year update for the commercial fishery. The commercial fishery was also the least sensitive to the scenario runs. The standard deviation for the median differences from the baseline for commercial fishermen welfare was 0.05 , whereas it was 0.48 and 0.69 for the consumers and recreational fishermen, respectively. 
Can. J. Fish. Aquat. Sci.

Fig. 5. CV [mil. 2014 USD] for relative change in summer flounder biomass and catch rates.

CV [mil.uSD]

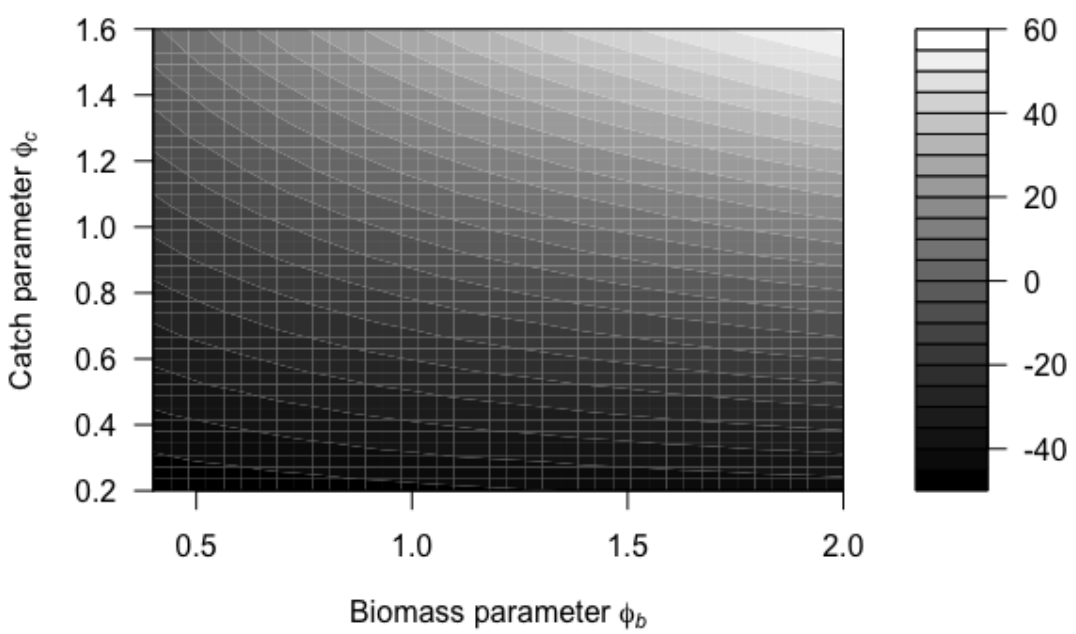

Fig. 6. Distribution of estimated recreational fisher welfare effects showing median value of differences in yearly average effect over the simulation period between the baseline scenario and alternative SA interval and DML.

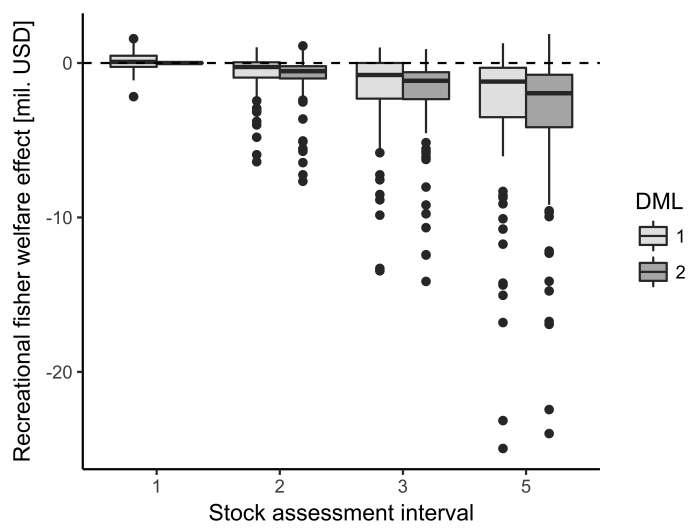

\section{Discussion and Conclusions}

There is increasing interest in applying management strategy evaluations to address a wide variety of issues in fisheries management, ranging from the appropriate sample size for aging of fish to how the incorporation of ecosystem effects will change the performance of harvest control rules. A challenge is providing a useful set of metrics by which to compare performance of the system under different scenarios. In this study we have demonstrated how to transform a set of biomass based metrics, catch and spawning stock biomass, to a measure of net economic benefit. In the specific case of summer 
Hutniczak et al.

Fig. 7. Total welfare effects over time for the baseline scenario (based on simulation medians). Subsequent shades of grey represent welfare effects components in order noted on the y-axis. Dashed lines represent quantiles of the simulated total value.

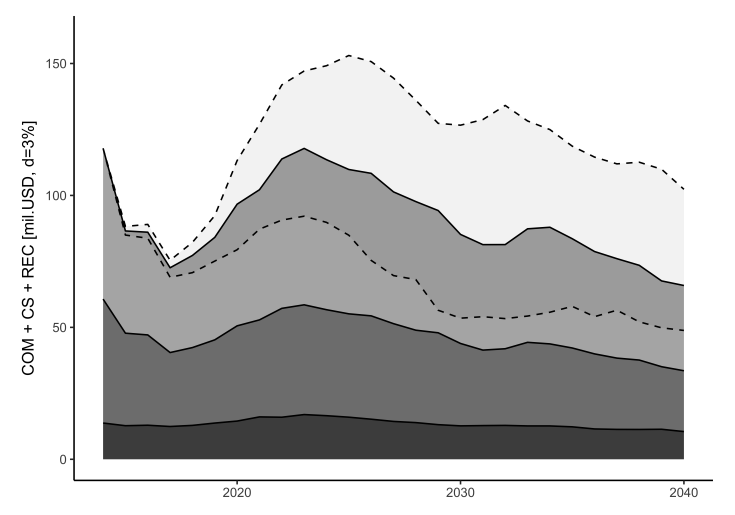

Table 8. Model results showing medians of differences in average annual value over the simulation period and aggregate between scenarios categorized by SA interval and DML and the base scenario and medians of aggregate welfare effects (in mil. USD).

\begin{tabular}{cccccc}
\hline SA interval & DML & Consumer & Commercial producer & Recreational fisher & Aggregate \\
\hline 1 & 1 & 0.19 & -0.07 & 0.07 & 2447.4 \\
1 & 2 & 0 & 0 & 0 & 2426.6 \\
2 & 1 & -0.07 & -0.03 & -0.26 & 2434.0 \\
2 & 2 & -0.46 & 0.01 & -0.53 & 2413.4 \\
3 & 1 & -0.39 & -0.06 & -0.78 & 2389.4 \\
3 & 2 & -0.83 & -0.05 & -1.15 & 2365.1 \\
5 & 1 & -0.83 & -0.05 & -1.20 & 2345.5 \\
5 & 2 & -1.20 & -0.15 & -1.96 & 2327.5 \\
\hline
\end{tabular}

flounder, we demonstrate that the relatively small differences in aggregate harvest over the simulation period due to the different assessment updates and data lags, can be magnified when quantified as net economic benefits. For example, the difference between a one year stock assessment update interval with a data lag of two years (base scenario), and a five year update interval with a two year data lag is only 10000 metric tons of fish harvested over a 27 year period. Our analysis estimates, however, that the difference in welfare between the two scenarios is about USD 99.1 million. The more frequent updating requires 21 more updates during our simulation period (27 updates vs. 6 updates). While no comprehensive analysis has been conducted for the cost of conducting stock assessment updates, Methot and Merrick looked at NMFS spending per region on stock assessments, and found that, on average, assessments costs USD 1.7 million. Given that a stock assessment update is probably less costly to conduct than a full benchmark stock assessment, it would be reasonable to conclude that the additional 21 updates would cost considerably less than USD 35.7 million, and would be more than compensated for in consumer and producer welfare in the summer flounder fishery.

The above comparison, while illustrative, does not account for the fact that these differences, while large, were not statistically significantly different. We caution, however, the conclusion that summer flounder stock assessments can be updated less frequently than they currently are with no loss in net economic value. Simplifying assumptions such as holding landings of all other species constant, disre- 
garding the role of the state-level allocation of the TAC, or the limited time series and representativeness of cost data for the fishing fleet are areas to be explored for model improvement. Other factors such as the state-by-state allocation of the could also factor into the analysis.

With limited budgets to conduct fish surveys and stock assessments, management agencies need to prioritize which stocks get assessed and how often. Our analysis for summer flounder provided estimates of returns to the summer flounder fishery (including consumers) of more frequent updating of stock assessments, but which species will see their assessments delayed in order to apply the limited capacity to summer flounder? Ideally, if an analysis was done similar to ours for all major species, the information could be used to determine the optimal frequency to conduct assessments, as the opportunity cost for not updating stock assessments for other species could be taken into consideration.

In lieu of a full economic analysis, there are certain indicators which would suggest which stocks should be updated most frequently. From the stock assessment, existence of a retrospective pattern in the data that results in over or underestimates of stock status, means that more frequent updating will uncover errors and avoid excess economic losses. As we have shown, price flexibility is an important indicator, not only in its ability to temper the economic impacts of commercial fishermen due to large swings in quota, but because of its representativeness of downstream impacts, as reflected in changes in consumer surplus. Similarly, the flexibility of fishing costs to quota and biomass would indicate the level of importance of frequent updating. Given the relative magnitude of net benefits to recreational fishermen, species with large directed recreational fisheries can also benefit greatly. Management agencies tend to focus on fisheries with large commercial value, and without an equivalent recreational value estimate, just include the recreational importance as a qualitative factor.

Similar to the underlying management strategy evaluation, the accompanying economic analysis is complex to create. However, once the underlying economic models have been parameterized, the capacity to examine a wide range of scenarios is greatly enhanced.

\section{Acknowledgements}

We wish to thank the two anonymous referees and the editor for their insightful comments and suggestions that significantly improved the manuscript.

\section{References}

Belotti F, Deb P, and Norton EC. 2015. twopm : Two-part models. The Stata Journal, 15(1):3-20.

Brown MG, Lee JY, and Seale JL. 1995. A Family of Inverse Demand Systems and Choice of Functional Form. Empirical Economics, 20:519-530.

Butterworth DS. 2007. Why a management procedure approach? Some positives and negatives. ICES Journal of Marine Science, 64:613-617.

Butterworth DS and Punt AE. 1999. Experiences in the evaluation and implementation of management procedures. ICES J Mar Sci, 56:985-998.

Charles AT. 1998. Living with uncertainty in fisheries: Analytical methods, management priorities and the Canadian groundfishery experience. Fisheries Research, 37(1-3):37-50.

Clark CW and Kirkwood GP. 1986. On Uncertain Renewable Resource Stocks : Optimal Harvest Policies and the Value of Stock Surveys. Journal of Environmental Economics and Management, $13: 235-244$.

Costello CJ, Adams RM, Polasky S, Costello CJ, Adams RM, and Polasky S. 1998. The Value of El Niño Forecasts in the Management of Salmon : A Stochastic Dynamic Assessment. American Jnl of Agricultural Economics, 80(4):765-777. 
Hutniczak et al.

Costello CJ, Polasky S, and Solow A. 2001. Renewable resource management with environmental prediction. Canadian Journal of Economics, 34(1):196-211.

Dickey DA and Fuller WA. 1979. Distribution of the estimators for autoregressive time series with a unit root. Journal of th American Statistical Association, 74(366a):427-431.

Eales J, Durham C, and Wessells CR. 1997. Generalized Models of Japanese Demand for Fish. American Journal of Agricultural Economics, 79(4):1153-1163.

Fournier DA, Skaug HJ, Ancheta J, Ianelli J, Magnusson A, Maunder MN, Nielsen A, and Sibert J. 2012. AD Model Builder: using automatic differentiation for statistical inference of highly parameterized complex nonlinear models. Optim Methods Softw, 27(2):233-249.

Fournier D and Archibald CP. 1982. A General Theory for Analyzing Catch at Age Data. Canadian Journal of Fisheries and Aquatic Sciences, 39(8):1195-1207.

Francis RICC and Shotten R. 1997. Risk in fisheries management: a review. Can J Fish Aquat Sci, 54: 1699-1715.

Gentner B, Kirkley JE, Hindsley PR, and Steinback S. 2010. Summer Flounder Allocation Analysis. NOAA Technical Memorandum, NMFS-F/SPO.

Haab TC and Mcconnell KE, 2003. Valuing Environmental and Natural Resources. Edward Elgar, Northampton, MA.

Hansen LP. 1982. Large sample properties of generalised method of moments estimators. Econometrica, 50(4):1029-1054.

Hicks R and Schnier KE. 2016. Commercial and Recreational Allocation for Summer Flounder. WP.

Holland DS and Herrera GE. 2009. Uncertainty in the management of fisheries: contradictory implications and a new approach. Marine Resource Economics, 24(3):289-299.

Jin D, Kitts A, and DePiper G. 2016. Estimation of Commercial Fishing Trip Costs Using Sea Sampling Data. Proceedings of the Eighteenth Biennial Conference of the International Institute of Fisheries Economics and Trade.

Kirkley JE and Strand IE. 1988. The Technology and Management of Multi-species Fisheries. Applied Economics, 20(10):1279-1292.

Lee MY and Thunberg E. 2013. An Inverse Demand System for New England Groundfish : Welfare Analysis of the Transition to Catch Share Management. American Journal of Agricultural Economics, 95:1178-1195.

Lewy P and Vinther M. 2004. Modelling stochastic age-length-structured multi-species stock dynamics. ICES CM, 20:1-33.

Mace PM, Bartoo NW, Hollowed AB, Kleiber P, Methot RD, Murawski SA, Powers JE, and Scott GP. 2001. Marine Fisheries Stock Assessment Improvement Plan Report of the National Marine Fisheries Service National Task Force for Improving Fish Stock Assessments. NOAA Technical Memorandum, NMFS-F/SPO.

Mcconnell KE and Strand IE. 1994. the Economic Value of Mid and South Atlantic Sportfishing. University of Maryland, College Park.

Published by NRC Research Press 
Can. J. Fish. Aquat. Sci.

Moxnes E. 2003. Uncertain measurements of renewable resources: Approximations, harvesting policies and value of accuracy. Journal of Environmental Economics and Management, 45(1):85-108.

Myrseth J, Enberg K, Heino M, and Fiksen O. 2011. Do accurate stock estimates increase harvest and reduce variability in fisheries yields? Natural Resource Modeling, 24(2):222-241.

Newey WK and West KD. 1987. A Simple Positive Semi-Definite, Heteroskedasticity and Autocorrelation Consistent Covariance Matrix. Econometrica, 55(3):703-708.

Newey WK and West KD. 1994. Automatic lag selection in covariance matrix estimation. The Review of Economic Studies, 61(4):631-653.

NOAA. 1999. Discounting and the treatment of uncertainty in natural resource damage assessment. National Oceanic and Atmospheric Administration, Damage Assessment and Restoration Program, Damage Assessment Center, Resource Valuation Branch, Silver Spring.

Park H, Thurman WN, and Easley JE. 2004. Modeling Inverse Demands for Fish: Empirical Welfare Measurement in Gulf and South Atlantic Fisheries. Marine Resource Economics, 19(3):333-351.

Prellezo R. 2017. Expected economic value of the information provided by fishery research surveys. Fish Res, 190:95-102.

Punt AE, Siddeek MSM, Garber-Yonts B, Dalton M, Rugolo L, Stram D, Turnock BJ, , and Zheng J. 2012. Evaluating the impact of buffers to account for scientific uncertainty when setting TACs: application to red king crab in Bristol Bay, Alaska. ICES Journal of Marine Science, 69:624-634.

Punt AE, Butterworth DS, de Moor CL, De Oliveira JAA, and Haddon M. 2016. Management strategy evaluation: best practices. Fish Fish, 17(2):303-334.

Reed WJ. 1979. Optimal escapement levels in stochastic and deterministic harvesting models. Journal of Environmental Economics and Management, 6(4):350-363.

Rincon MM, Mumford JD, Levontin P, Leach AW, and Ruiz J. 2016. The economic value of environmental data: a notional insurance scheme for the European anchovy. ICES Journal of Marine Science, 73(4):1033-1041.

Sethi G, Costello CJ, Fisher A, Hanemann M, and Karp L. 2005. Fishery management under multiple uncertainty. Journal of Environmental Economics and Management, 50(2):300-318.

Shertzer KW and Prager MH. 2007. Delay in fishery management: Diminished yield, longer rebuilding, and increased probability of stock collapse. ICES Journal of Marine Science, 64(1):149-159.

Shertzer KW, Prager MH, and Williams EH. 2008. A probability-based approach to setting annual catch levels. Fishery Bulletin, 106(3):225-232.

Smith ADM, Sainsbury KJ, and Stevens RA. 1999. Implementing effective fisheries-management systemsmanagement strategy evaluation and the Australian partnership approach. ICES J Mar Sci, 56:967-979.

Tahvonen O, Quaas MF, Schmidt JO, and Voss R. 2013. Optimal Harvesting of an Age-Structured Schooling Fishery. Environmental and Resource Economics, 54:21-39.

Terceiro M. 2015. Stock Assessment Update of Summer Flounder for 2015. NOAA Fisheries, Northeast Fisheries Science Center, Woods Hole. 
Hutniczak et al.

Walters CJ. 1996. Stock information requirements for quota management systems in commercial fisheries. Reviews in Fish Biology and Fisheries, 42:21-42.

Wiedenmann J, Wilberg M, Sylvia A, and Miller T. 2017. An evaluation of acceptable biological catch $(\mathrm{ABC})$ harvest control rules designed to limit overfishing. Canadian Journal of Fisheries and Aquatic Sciences, 74(7):1028-1040.

Zimmermann F and Enberg K. 2017. Can less be more? Effects of reduced frequency of surveys and stock assessments. ICES J Mar Sci, 74(1):56-68. 


\section{Appendix A: Summer flounder MSE model details}

The simulation model for summer flounder model was split into a historical and management period. Population and fishery dynamics during the historical period are fixed based on the 2015 stock assessment. The fixed dynamics include the abundance and fishery selectivity at age, the total catch, mean weight and maturity ate age, and the assumed natural mortality rate. The time period of the his-torical period was from 1982 to 2015.

Summer flounder population and fishery dynamics were stochastic in the future period, with the equations governing these dynamics presented in table A.1, definitions of the variables in table A.2, and parameters defined in table A.3. These equations are referenced by their number in table A.1, such that the formula for calculating recruitment is referred to as eq. S1. Recruitment followed the BevertonHolt stock-recruit relationship, with bias-corrected lognormally distributed and autocorrelated deviations (eq. S1). Parameters for the summer flounder stock-recruit relationship were estimated using a maximum likelihood approach with the estimates of spawning biomass and recruitment from the stock assessment. Total spawning biomass in a given year was calculated by summing the product of the proportion mature, weight at age and abundance at age over all recruited age classes (eq. S2). Annual abundance of recruited ages was determined from the abundance of that cohort the previous year, decreased by continuous natural and fishing mortality (eq. S3). Total mortality at age was the sum of fishing and natural mortality (eq. S4). Natural mortality was independent of age, but varied over time following an autocorrelated process on the log scale (eq. S5). Fishing mortality at age was the product of fishing intensity of fully selected ages and selectivity at age. The model contained a single fishery dome-shaped selectivity, which varied over time in the historical period based on the estimated selec-tivities, and was assumed fixed over time in the future period (eq. S6). Weight and maturity at age were fixed over time in the historical period at the observed values, and fixed during the future period as the average over the most recent five years for a given age class.

The data used in the assessment were the fishery catch (both total and proportions at age) and a fisheryindependent index of abundance (both total and proportions at age). These data sets were generated by applying observation error to the true values using lognormal errors for the total index and catch, and multinomial distributions for the age compositions (eqs. S7 - S11). The time series of catch and survey data were input into the SCAA model to estimate the abundance at age, fishing mortality rates in each year, and reference points for management. Model parameters within the SCAA were estimated using a maximum likelihood approach, with the specific parameters estimated the abundance at age in the first year, recruitments and fishing mortality rates (across years), fishery selectivity parameters, survey selectivity parameters, and survey catchability. Survey catchability and age at peak selectivity in the fishery are assumed constant over time in the assessment model, even though they were varied with time in the operating model. Natural mortality in the assessment was assumed to be constant over age and time at the mean value (table A.3). All other required SCAA inputs (i.e., maturity and weight at age) are set to the true values specified in the operating model. The SCAA model also estimated the spawning potential ratio (SPR) based reference points for summer flounder, using an SPR limit of 0.35. The MAFMC harvest control rule control rule was applied using the estimated biomass projected by from the terminal assessment year over the interval between assessments. The projected biomass in the first one or two year (determined by the data lag) was calculated using the terminal abundance at age, fixed weight at age, assumed $\mathrm{M}$ and estimated $\mathrm{F}$ at age in the terminal year (assumed to be the same F for both years with a data lag of 2 years), with recruitment assumed equal to the esti-mated mean. Biomass over the remaining years (determined by the specified assessment interval) was projected done in the same manner, but by fishing at the estimated FMSY to produce estimates of the OFL. The MAFMC control rule then applies a buffer to set the ABC, with the size of the buffer biomass-dependent. The estimated spawning biomass ratio (S / SMSY) in each projected year is used to calculate the size of the buffer in setting the ABC. The estimated ABC is then removed from the population the each year over the assessment interval, and the resulting $\mathrm{F}$ is calculated using the Bara-nov catch equation. 
Table A.1. Equations governing the population and data-generating dynamics in the operating model.

S1 Stock-recruit relationship

$R(t)=\frac{S\left(t-a_{R}\right)}{\alpha+\beta S\left(t-a_{R}\right)} e^{\varepsilon_{R}-0.5 \sigma_{R}^{2}}$

$\alpha=\frac{S_{0}(1-h)}{4 h R_{0}} \quad \beta=\frac{5 h-1}{4 h R_{0}}$

$\varepsilon_{R}(t)=\rho_{R} \varepsilon_{R}(t-1)+\sqrt{1-\rho_{R}^{2}} \varphi_{R}(t)$

$\varphi_{R}(t) \sim N\left(0, \sigma_{R}^{2}\right)$

S2 Spawning biomass

$S(t)=\sum_{a} m(a) w(a) N(a, t)$

S3 Numerical abundance at age

$$
N(a, t)=\left\{\begin{array}{lc}
R(t) & a=a_{R} \\
N(a-1, t-1) e^{-Z(a-1, t-1)} & a_{R}<a<a_{\max } \\
N(a, t-1) e^{-Z(a-1, t-1)}+N(a, t-1) e^{-Z(a, t-1)} & a=a_{\max }
\end{array}\right.
$$

S4 Total mortality

$$
Z(a, t)=M(t)+s_{f}(a, t) F(t)
$$

S5 Time-varying natural mortality

$$
\begin{aligned}
& M(t)=M(t-1) e^{\varepsilon_{M(t)}-0.5 \sigma_{M}^{2}} \\
& \varepsilon_{M}(t)=\rho_{M} \varepsilon_{M}(t-1)+\sqrt{1-\rho_{M}^{2}} \varphi_{M}(t) \\
& \varphi_{M}(t) \sim N\left(0, \sigma_{M}^{2}\right)
\end{aligned}
$$

S6a Logistic selectivity at age in fishery or survey, with time varying selectivity only in the fishery $s_{s}(a, t)=1 /\left(1+e^{-\frac{a-s_{50 \%}}{s_{\text {slope }}}}\right)$

S6b Dome-shaped selectivity at age in fishery

$s_{f}(a, t)\left\{\begin{array}{lc}e^{\frac{-\left(a-s_{\text {mid }}(t)\right)}{s_{u} p}} & a \leq s_{\text {mid }} \\ e^{\frac{-\left(a-s_{\text {mid }}\right)}{s_{\text {down }}}} & a>s_{\text {mid }}\end{array}\right.$

$s_{\text {mid }}(t)=s_{\text {mid }}(t-1) e^{\varepsilon_{s}(t)-0.5 \sigma_{s}^{2}}$

$\varepsilon_{s}(t)=\rho_{s} \varepsilon_{s}(t-1)+\sqrt{1-\rho^{2}} \varphi(t)$

$\varphi(t) \sim N\left(0, \sigma_{s}^{2}\right)$

S7 Annual catch at age and total catch

$$
\begin{aligned}
& C(a, t)=\frac{s_{f}(a, t) F(t)}{Z(a, t)} w(a) N(a, t)\left(1-e^{-Z(a, t)}\right) \\
& C(t)=\sum_{a} C(a, t)
\end{aligned}
$$

S8 Observed catch

$$
\begin{aligned}
& C_{o b s}(t)=C(t)^{\varepsilon_{C}(t)-0.5 \sigma_{C}^{2}} \\
& \varepsilon_{C}(t) \sim N\left(0, \sigma_{C}^{2}\right)
\end{aligned}
$$

S9 True index of abundance

$$
\begin{aligned}
& I(a, t)=q(t) s_{s}(a) N(a, t) \\
& I(t)=\sum_{a} I(a, t) \\
& q(t)=q(t-1) e^{\varepsilon_{q}(t)-0.5 \sigma_{q}^{2}} \\
& \varepsilon(t) \sim N\left(0, \sigma_{q}^{2}\right)
\end{aligned}
$$

S10 Observed index of abundance

$$
I_{o b s}(t)=I(t)^{\varepsilon_{I}(t)-0.5 \sigma_{I}^{2}}
$$$$
\varepsilon_{I}(t) \sim N\left(0, \sigma_{I}^{2}\right)
$$

S11 Observed vector of proportion at age in fishery $f$

$\boldsymbol{p}_{\text {obs }}(t)=(1 / n) \boldsymbol{\Theta}(t)$

$\boldsymbol{\Theta}(t) \sim \operatorname{Multinomial}(n, \boldsymbol{p}(t))$

$\boldsymbol{p}(t)(1 / I(t))\left(I\left(a_{R}, t\right), \ldots, I\left(a_{\max }, t\right)\right)$ 
Table A.2. Description of the index and state variables used in equations in the model (presented in Table A.1).

\begin{tabular}{|c|c|}
\hline Symbol & Description \\
\hline & Index variables \\
\hline $\bar{t}$ & Year \\
\hline \multirow[t]{2}{*}{$a$} & Age \\
\hline & State variables \\
\hline$N$ & Numerical abundance \\
\hline$S$ & Spawning biomass $(\mathrm{kg})$ \\
\hline$L$ & Length $(\mathrm{cm})$ \\
\hline$w$ & Weight (kg) \\
\hline$m$ & Maturity (proportion) \\
\hline$s_{s}$ & Survey selectivity (proportion) \\
\hline$s_{f}$ & Fishery selectivity (proportion) \\
\hline$F$ & Fishing mortality rate $\left(\right.$ year $^{-1}$ ) \\
\hline$M$ & Natural mortality rate \\
\hline$Z$ & Total mortality rate $\left(\right.$ year $^{-1}$ ) \\
\hline$C$ & Total fishery catch $(\mathrm{kg})$ \\
\hline$C_{o b s}$ & Observed fishery catch $(\mathrm{kg})$ \\
\hline$p_{C}$ & Proportions at age in catch \\
\hline$p_{C, o b s}$ & Observed proportion at age in catch \\
\hline$I$ & Survey numerical index of abundance \\
\hline$I_{o b s}$ & Observed survey numerical index of abundance \\
\hline$q$ & Survey catchability \\
\hline$p_{I}$ & Proportions at age in survey \\
\hline$p_{I, o b s}$ & Observed proportion at age in survey \\
\hline
\end{tabular}


Table A.3. Parameter values used in the model for summer flounder.

\begin{tabular}{clc}
\hline Parameter & Description & Value \\
\hline$a_{R}$ & Age at recruitment (to population) & 1 \\
$a_{\text {max }}$ & Maximum age (a plus group) & 8 \\
$M(t-1)$ & Starting natural mortality rate & 0.25 \\
$\sigma_{M}$ & Standard deviation of time-varying $M$ & 0.10 \\
$\rho_{M}$ & Autocorrelation in $M$ & 0.30 \\
$h$ & Steepness & 0.90 \\
$R_{0}$ & Virgin recruitment & 48000 \\
$S_{0}$ & Unfished spawning biomass & 150000 \\
$\sigma_{R}$ & Standard deviation of stock-recruit relationship & 0.50 \\
$\rho_{R}$ & Autocorrelation in recruitment & 0.44 \\
$s_{m i d}(t=1)$ & Age at maximum selectivity in dome-shaped function & 5.00 \\
$s_{u p}, s_{d o w n}$ & Controls how rapidly selectivity increases/decreases & $1.73 / 5.44$ \\
$\sigma_{s}$ & Standard deviation of age at 50\% of peak selectivity & 0.15 \\
$\rho_{s}$ & Autocorrelation in selectivity & 0.20 \\
$s_{50 \%}(t-1)$ & Starting age at 50\% selectivity in survey & 0.50 \\
$s_{\text {slope }}$ & Slope of survey selectivity function & 1.00 \\
$\sigma_{C}$ & Standard deviation of catch estimates & 0.20 \\
$\sigma_{I}$ & Standard deviation of survey estimates & 0.29 \\
$q(t=1)$ & Mean catchability in survey & $5 \times 10^{-5}$ \\
$\sigma_{q}$ & Standard deviation of catchability random walk & 0.05 \\
$n_{C}$ & Effective sample size of the catch & 100 \\
$n_{I}$ & Effective sample size of the survey & 100 \\
$S P R_{M S Y}$ & Spawning potential ratio (SPR) that defines overfishing & 0.35 \\
$F_{M S Y}$ & Fishing mortality rate that defines overfishing & 0.30 \\
\hline & &
\end{tabular}




\section{Appendix B: Demand model estimates}

Table B.1. Coefficients of the SIDS model.

\begin{tabular}{cccc}
\hline Coefficient & Estimate & $\mathrm{SE}$ & $\mathrm{p}$ \\
\hline$\alpha_{1}$ & 0.0002 & 0.0003 & 0.594 \\
$\alpha_{2}$ & -0.0017 & 0.0003 & 0.000 \\
$\alpha_{3}$ & 0.0008 & 0.0007 & 0.220 \\
$\alpha_{4}$ & -0.0013 & 0.0009 & 0.169 \\
$\alpha_{5}$ & 0.0020 & 0.0014 & 0.136 \\
$\pi_{1}$ & -0.0108 & 0.0135 & 0.425 \\
$\pi_{2}$ & -0.0218 & 0.0160 & 0.172 \\
$\pi_{3}$ & 0.0508 & 0.0278 & 0.068 \\
$\pi_{4}$ & -0.0294 & 0.0343 & 0.392 \\
$\pi_{5}$ & -0.0057 & 0.1317 & 0.966 \\
$\pi_{11}$ & -0.0113 & 0.0112 & 0.317 \\
$\pi_{12}$ & -0.0130 & 0.0012 & 0.000 \\
$\pi_{13}$ & 0.0104 & 0.0025 & 0.000 \\
$\pi_{14}$ & -0.0041 & 0.0019 & 0.029 \\
$\pi_{15}$ & 0.0179 & 0.0105 & 0.089 \\
$\pi_{22}$ & -0.0232 & 0.0129 & 0.072 \\
$\pi_{23}$ & -0.0076 & 0.0019 & 0.000 \\
$\pi_{24}$ & 0.0047 & 0.0022 & 0.034 \\
$\pi_{25}$ & 0.0390 & 0.0129 & 0.002 \\
$\pi_{33}$ & 0.0095 & 0.0195 & 0.627 \\
$\pi_{34}$ & -0.0181 & 0.0016 & 0.000 \\
$\pi_{35}$ & 0.0058 & 0.0181 & 0.750 \\
$\pi_{44}$ & -0.0135 & 0.0270 & 0.616 \\
$\pi_{45}$ & 0.0309 & 0.0272 & 0.255 \\
$\pi_{55}$ & -0.0937 & 0.0680 & 0.168 \\
$\theta_{1}$ & 0.9832 & 0.2201 & 0.000 \\
$\theta_{2}$ & 0.1282 & .2081 & 0.538 \\
\hline & & &
\end{tabular}

Note: Parameters derived from constraints in italics. 


\section{Appendix C: Site quality model estimates}

Table C.1. Two-part model results for summer flounder $(s=\mathrm{SF})$.

\begin{tabular}{lccc}
\hline Coefficient & Estimate & SE & $\mathrm{p}$ \\
\hline Logit: $\alpha_{b}$ & 1.177 & 0.179 & 0.000 \\
Logit: $\alpha_{h}$ & 1.187 & 0.022 & 0.000 \\
Logit: $\alpha_{e}$ & 0.191 & 0.007 & 0.000 \\
Logit: $\alpha_{H D}$ & 1.352 & 0.041 & 0.000 \\
Logit: $\alpha_{P R}$ & 1.162 & 0.038 & 0.000 \\
Logit: $\alpha_{0}$ & -2.023 & 0.469 & 0.000 \\
\hline GLM: $\alpha_{b}$ & 0.149 & 0.097 & 0.125 \\
GLM: $\alpha_{h}$ & 0.576 & 0.012 & 0.000 \\
GLM: $\alpha_{e}$ & 0.110 & 0.004 & 0.000 \\
GLM: $\alpha_{H D}$ & .067 & 0.028 & 0.016 \\
GLM: $\alpha_{P R}$ & 0.271 & 0.027 & 0.000 \\
GLM: $\alpha_{0}$ & -0.017 & 0.271 & 0.949 \\
\hline$\alpha_{w, l}$ jointly $\chi^{2}(296)$ & 4871.33 & & 0.000 \\
\hline Log pseudolikelihood & -131284.84 & & \\
Number of observations & 58903 & & \\
\hline
\end{tabular}

Table C.2. Two-part model results for small game fish $(s=\mathrm{SG})$.

\begin{tabular}{lccc}
\hline Coefficient & Estimate & SE & $\mathrm{p}$ \\
\hline Logit: $\alpha_{h}$ & 0.842 & 0.038 & 0.000 \\
Logit: $\alpha_{e}$ & 0.180 & 0.016 & 0.000 \\
Logit: $\alpha_{H D}$ & 1.362 & 0.078 & 0.000 \\
Logit: $\alpha_{P R}$ & 0.578 & 0.059 & 0.000 \\
Logit: $\alpha_{0}$ & -1.967 & 0.217 & 0.000 \\
\hline GLM: $\alpha_{h}$ & 0.170 & 0.035 & 0.000 \\
GLM: $\alpha_{e}$ & 0.088 & 0.013 & 0.000 \\
GLM: $\alpha_{H D}$ & 0.265 & 0.066 & 0.000 \\
GLM: $\alpha_{P R}$ & 0.100 & 0.057 & 0.082 \\
GLM: $\alpha_{0}$ & 1.541 & 0.182 & 0.000 \\
\hline$\alpha_{w, l}$ jointly $\chi^{2}(440)$ & 1754.99 & & 0.000 \\
\hline Log pseudolikelihood & -7205.60 & & \\
Number of observations & 12134 & & \\
\hline
\end{tabular}


Table C.3. Two-part model results for bottom fish $(s=\mathrm{BT})$.

\begin{tabular}{lccc}
\hline Coefficient & Estimate & SE & $\mathrm{p}$ \\
\hline Logit: $\alpha_{h}$ & 1.118 & 0.099 & 0.000 \\
Logit: $\alpha_{e}$ & 0.056 & 0.036 & 0.117 \\
Logit: $\alpha_{H D}$ & 1.247 & 0.178 & 0.000 \\
Logit: $\alpha_{P R}$ & 1.220 & 0.145 & 0.000 \\
Logit: $\alpha_{0}$ & -2.426 & 0.871 & 0.005 \\
\hline GLM: $\alpha_{h}$ & 0.436 & 0.047 & 0.000 \\
GLM: $\alpha_{e}$ & 0.090 & 0.015 & 0.000 \\
GLM: $\alpha_{H D}$ & 0.497 & 0.095 & 0.000 \\
GLM: $\alpha_{P R}$ & 0.548 & 0.086 & 0.000 \\
GLM: $\alpha_{0}$ & 0.864 & 0.489 & 0.077 \\
\hline$\alpha_{w, l}$ jointly $\chi^{2}(232)$ & 1579.20 & & 0.000 \\
\hline Log pseudolikelihood & -1483.60 & & \\
Number of observations & 3564 & & \\
\hline
\end{tabular}

